\title{
Predicting the firing phase of an oscillatory neuron from its impedance profile
}

\author{
Farzan Nadim ${ }^{1,2^{*}}$, Horacio G Rotstein ${ }^{2}$, David Fox ${ }^{1}$ \\ From Twenty Second Annual Computational Neuroscience Meeting: CNS*2013 \\ Paris, France. 13-18 July 2013
}

The activity phase of a neuron in an oscillatory network often determines what the neuron codes $[1,2]$. We are interested in understanding the effect of subthreshold factors that influence this activity phase. Here we develop a first-order approximation of the activity phase of a neuron receiving oscillatory input using its subthreshold impedance profile.

A neuron's subthreshold membrane potential response to sinusoidal current input with frequency $f$ is sinusoidal (to first order) with amplitude and phase-shift approximated by the impedance value at $f: Z_{f}=\left\|Z_{f}\right\| e^{i \varphi_{f}}$. If a neuron receives suprathreshold oscillatory input at frequency $f$, the resulting change in membrane potential can be approximated with a similar amplitude and phase-shift up to the time point $t_{\text {spike }}$ where spike threshold is reached. This results in the following simple equation: $V_{m}\left(t_{\text {spike }}\right)=V_{\text {rest }}+A_{\text {in }}\left\|Z_{f}\right\| \sin \left(2 \pi f \cdot t_{\text {spike }}+\varphi_{f}\right)=V_{\text {thresh }}$ where $A_{i n}$ is the amplitude of the input current. Assuming the reference time point of $t_{0}=0$ in the cycle, the spike phase can be approximated as $\varphi_{\text {spike }}=f \cdot t_{\text {spike }}=\frac{1}{2 \pi}\left(\arcsin \frac{V_{\text {thresh }}-V_{\text {rest }}}{A_{\text {in }}\left\|Z_{f}\right\|}-\varphi_{f}\right)$. This approximation is valid so long as the argument of arcsin is $<1$ in absolute value.

As proof of principle, we used the impedance profile of a model neuron exhibiting subthreshold resonance to approximate the spike phase with a given preset spike threshold (Figure A). We also used this approximation to predict the phase of the first spike in bursting PY neurons in the crab pyloric CPG, when synaptically isolated and subjected to a sinusoidal current input at different frequencies (0.1-4 Hz; see [3] for method). The PY

\footnotetext{
* Correspondence: farzan@njit.edu

'Department of Biological Sciences, NJIT-Rutgers University, Newark, NJ 07102, USA

Full list of author information is available at the end of the article
}

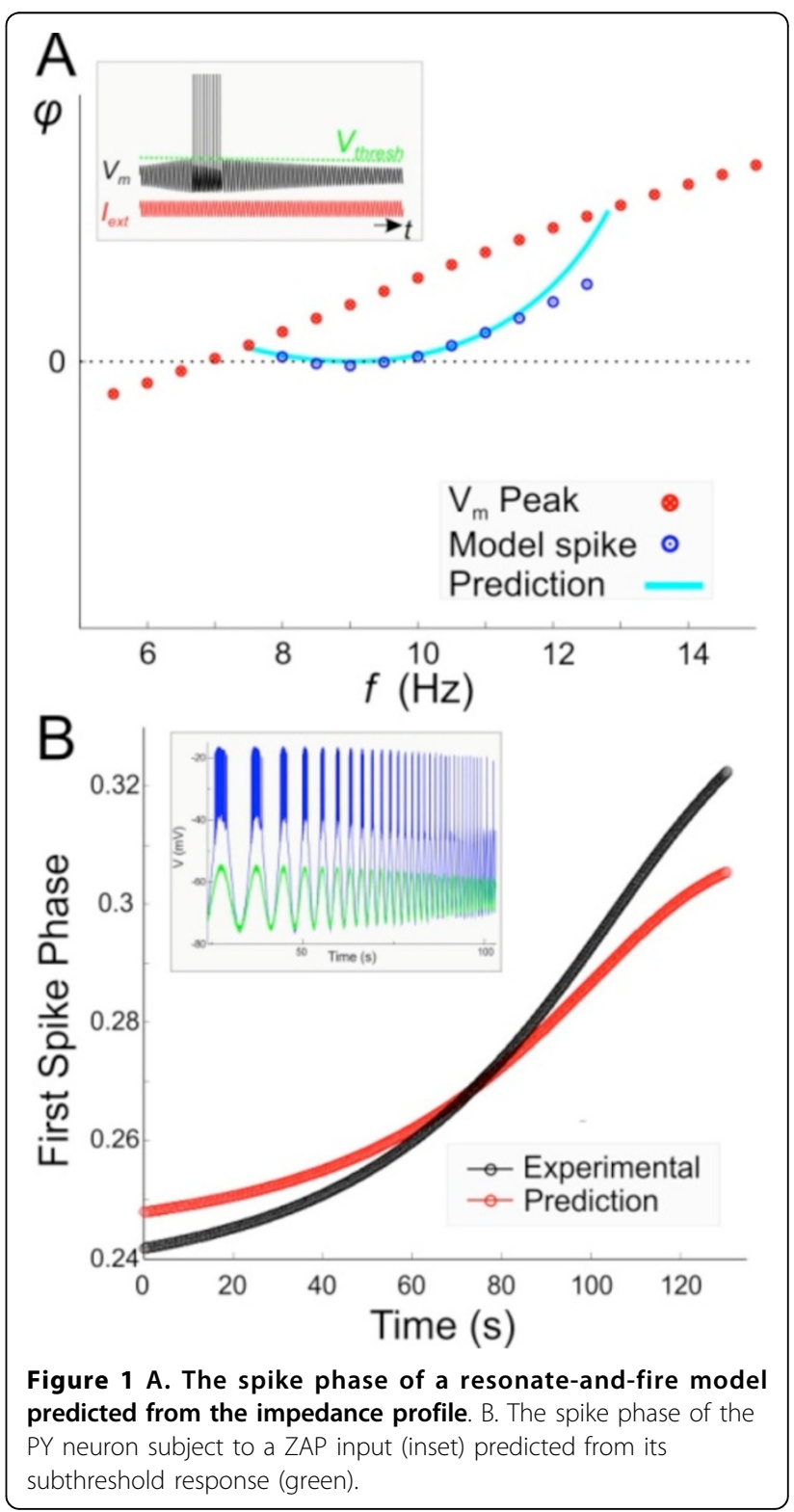

(c) 2013 Nadim et al; licensee BioMed Central Ltd. This is an Open Access article distributed under the terms of the Creative Commons :HW Central Attribution License (http://creativecommons.org/licenses/by/2.0), which permits unrestricted use, distribution, and reproduction in any medium, provided the original work is properly cited. 
impedance was measured from its subthreshold response.

To our knowledge this method, despite its simplicity, has not been previously used for the approximation of spike phase using the impedance profile. The usefulness of this approximation is that changes in membrane properties due to network activity or neuromodulation can be readily measured in the impedance profile and this knowledge can be used to predict how the neuron changes its response phase during network activity.

There are three sources of error in this approximation. First, the membrane impedance in biological neurons is nonlinear and does not scale linearly with the amplitude of the input current, especially when the neuron transitions from sub- to suprathreshold activity. However, the shift in membrane impedance can be tracked in both model and biological neurons. Second, spike threshold is dependent on input frequency. This dependence can also be tracked. Third, because of nonlinearities, the membrane potential response of a neuron is not perfectly sinusoidal. As seen in Figure 1B, despite these (nonlinear) sources of error, our method can provide a good approximation of spike phase. We are in the process of estimating spike phase in response to synaptic inputs arriving at a fixed frequency.

\section{Acknowledgements}

Supported by NIH MH060605 (FN), NSF DMS0817241 (HGR).

\section{Author details}

${ }^{1}$ Department of Biological Sciences, NJIT-Rutgers University, Newark, NJ 07102, USA. ²Department of Mathematical Sciences, NJIT, Newark, NJ 07102, USA

Published: 8 July 2013

\section{References}

1. Bose A, Manor $Y$, Nadim F: The activity phase of postsynaptic neurons in a simplified rhythmic network. J Comput Neurosci 2004, 17(2):245-261.

2. Geisler C, Robbe D, Zugaro M, Sirota A, Buzsaki G: Hippocampal place cell assemblies are speed-controlled oscillators. Proc Natl Acad Sci USA 2007, 104(19):8149-8154.

3. Tseng HA, Nadim F: The membrane potential waveform of bursting pacemaker neurons is a predictor of their preferred frequency and the network cycle frequency. J Neurosci 2010, 30(32):10809-10819.

doi:10.1186/1471-2202-14-S1-P132

Cite this article as: Nadim et al:. Predicting the firing phase of an oscillatory neuron from its impedance profile. BMC Neuroscience 201314 (Suppl 1):P132.

\section{Submit your next manuscript to BioMed Central} and take full advantage of:

- Convenient online submission

- Thorough peer review

- No space constraints or color figure charges

- Immediate publication on acceptance

- Inclusion in PubMed, CAS, Scopus and Google Scholar

- Research which is freely available for redistribution

Submit your manuscript at www.biomedcentral.com/submit 